\title{
ARTÍCULO
}

\section{La teoría sociológica del derecho europea y las concepciones jurídicas del zapatismo mexicano \\ The European sociological theory of law and the legal conceptions of the mexican zapatismo}

\author{
María Luisa Sorinao González \\ Área de Filosofía del Derecho \\ Universidad Pablo de Olvaide
}

Fecha de recepción 28/12/2019 | De aceptación: 03/06/2019 | De publicación: 27/06/2019

\section{RESUMEN.}

Los críticos del positivismo legalista en la transición del siglo XIX al XX -Gény, Ehrlich, Kantorowizenfrentaron una concepción plural del derecho a la ley como única fuente formal del derecho y al Estado como una única fuente material del derecho. La semejanza de estos críticos y el derecho indígena en general -y en particular el derecho indígena zapatista- es asombrosa tanto en lo que respecta a la defensa de una pluralidad de normas como a la génesis y formación histórica de las mismas

\section{PALABRAS CLAVE.}

zapatismo, derecho indígena, pluralismo jurídico, sociología del derecho.

\section{ABSTRACT.}

The critics of legalistic positivism in the transition from the nineteenth to the twentieth centuries -Gény, Ehrlich, Kantorowiz- were opposed to a plural conception of the law to the law as the only formal source and the state as a only material source of law. The similarity between these critics and indigenous law in general -and indigenous zapatista law in particular- is amazing as much in respect to the defense of a plurality of rules as to their origin and historical development.

\section{KEY WORDS.}

zapatismo, indigenous law, legal pluralism, sociology of law. 
Sumario: 1. Introducción. 2. Una breve historia de la revolución zapatista de chiapas. 3. La escuela sociológica francesa. François Gény (1861-1938): la defensa de la pluralidad de fuentes del derecho frente al monopolio de la ley. 3.1. F. Gény: La crítica al positivismo legalista decimonónico y al monopolio de la ley. 3.2. F. Gény: La construcción de una nueva técnica jurídica: la pluralidad de fuentes formales del derecho. 4. El movimiento de derecho libre. Eugen Ehrlich (18621922) y Hermann Kantorowicz (1877-1940) la pluralidad de derechos. 4.1. E. Ehrlich: Las etapas de su pensamiento jurídico. 4.2. E. Ehrlich: La pluralidad de derechos. 4.3. H. Kantorowicz: la prioridad de la jurisprudencia como fuente del derecho. 5. La teoria sociológica del derecho europea y las concepciones jurídicas zapatistas en méxico. 6. Conclusiones. 7. Bibliografía.

\section{Introducción}

Mientras leía los documentos de la revolución indígena zapatista de Chiapas, que se inicia el 1 de enero de 1994 y llega hasta nuestros días, escenario de mi tesis doctoral, me venían a la mente algunos párrafos de las obras de los primeros sociólogos del derecho críticos con el positivismo legalista en la primera mitad del siglo XX -Gény, Ehrlich, Kantorowicz-. Me prometía que algún día emprendería un análisis comparativo entre estos grandes maestros de la sociología jurídica y los testimonios menos conocidos del derecho indígena zapatista. Tal día ha llegado, y procedo a continuación al desarrollo del prometido examen comparativo.

El objetivo del trabajo es por lo tanto realizar un análisis comparativo, a cuyo efecto tengo que entresacar textos relevantes y conocidos de los sociólogos del derecho europeos y efectuar su comparación con los textos e ideas de las comunidades indígenas zapatistas. Por consiguiente la primera parte del presente trabajo es una sistematización y selección de textos de los citados sociólogos. La segunda, más original, intenta entresacar ideas y textos zapatistas en la misma línea de los anteriores textos europeos. Mi dedicación al estudio de la sociología del derecho y el pluralismo jurídico como tema de investigación preferente me permite partir de un bagaje de conocimientos adecuado para llevar a cabo la citada comparación y responder a la hipótesis central de este artículo: ¿Es posible establecer un parangón entre los primeros sociólogos del derecho europeos y el derecho indígena zapatista? Tras el desarrollo del cuerpo de la investigación encontraremos en las conclusiones una respuesta a la formulación de esta hipótesis.

La estructura de este trabajo es sencilla. Primero: las concepciones jurídicas de los primeros sociólogos del derecho. Segundo: el contrate de las concepciones jurídicas de los sociólogos citados con las ideas acerca del derecho presentes en documentos y testimonios de los zapatistas. Es necesario exponer las ideas principales de los sociólogos del derecho europeos para contrastarlas a continuación 
con las concepciones del zapatismo mexicano. Previamente dedico un epígrafe para situar el marco histórico del discurso, la evolución de la revolución zapatista, alrededor de la cual se gestan las concepciones acerca del derecho que quiero contrastar con los juristas-sociólogos europeos de la primera mitad del siglo XX.

Quiero destacar también el carácter pionero de este trabajo centrado en un análisis de elementos, que hasta donde llegan mis noticias no ha sido realizado hasta la fecha. Esto dota de originalidad al propósito del trabajo, pero al mismo tiempo le hace perfectible si otros investigadores siguen en el futuro por esta senda. Creo que su valor reside en abrir un camino que quizás otros estudiosos andarán con mejor ritmo y resultados.

De todas maneras no planteo la excepcionalidad del zapatismo chiapaneco, como caso aislado en América Latina, porque una posición semejante en la defensa de la autonomía política y de un derecho autóctono diferenciado y en lucha contra la ley dominante del Estado liberal podemos advertirla claramente en otros pueblos y comunidades indígenas de América Latina.

\section{Una breve historia de la revolución zapatista de chiapas}

Antes de la comparación de la teoría sociológico-jurídica europea y el zapatismo mexicano unos breves apuntes iniciales para que el lector no versado en la materia conozca los hitos históricos más destacados de la revolución zapatista de Chiapas, que se caracteriza por ser una revolución muy documentada plagada de numerosas fuentes directas. ${ }^{1}$ De estas fuentes se han hecho numerosos elencos o compendios ya desde los inicios de la revolución. ${ }^{2}$ Además de esta extraordinaria documentación,

\footnotetext{
${ }^{1}$ Las fuentes directas de la revolución zapatista son las sucesivas declaraciones de la Selva Lacandona, irremplazables para conocer las motivaciones, los objetivos y el proceso de la revolución zapatista, así como la Treceava Estela, por las mismas razones. Frecuentemente una nueva Declaración de la Selva Lacandona supone un cambio de rumbo de la revolución. La Sexta Declaración de la Selva Lacandona, la más relevante de las declaraciones, en 2005 comunicó y promovió la apertura de la revolución a otros sectores progresistas iniciando una nueva campaña. Y la Treceava Estela en 2003 dio a conocer la creación de las Juntas de Buen Gobierno, cumbre del desarrollo de la autonomía política zapatista, y el repliegue del ejército zapatista hacia funciones puramente militares. En este conjunto de textos considero de especial importancia un documento que suele pasar desapercibido, el titulado Siete pensamientos en mayo de 2003, porque contiene la filosofía política del subcomandante Marcos, jefe militar del ejército zapatista, la persona con seguridad más influyente en la historia de la revolución zapatista. Junto a estos textos básicos el nutrido conjunto de documentos de dos colecciones, la de la editorial Era y la de la editorial Ediciones del Serbal. En la bibliografía figuran los datos completos de estos documentos, a los que remiten las citas de este trabajo.

${ }^{2}$ Cito algunas compilaciones al uso: Acuerdos de San Andrés sobre "Derechos y Cultura Indígena"; Chiapas: la palabra de los armados de verdad y fuego, 2 vols., Barcelona, Ediciones del Serbal, 1994; EZLN, Documentos y comunicados I-IV, México, Era, 1994-2003; EZLN, Libertad, democracia y justicia, delirio del EZLN, México, s/e,1996; EZLN, Declaraciones de la Selva Lacandona, I-VI, México, s/e, 1993; SUBCOMANDANTE MARCOS y LE BOT, YVON, El sueño zapatista, Barcelona, Anagrama, 1997; SUBCOMANDANTE MARCOS, La Treceava Estela, Julio de 2003. SUBCOMANDANTE MARCOS. Desde las montañas del sureste
} 
ayudada por la facilidad de la comunicación en internet, la bibliografía sobre la revolución, que gozó de una difusión internacional, es inabarcable. ${ }^{3}$ Imposible dedicar mi atención a las numerosas fuentes indirectas, de la que en nota a pie de página hago una selección. ${ }^{4}$

La revolución se inicia con la rebelión de las comunidades indígenas chiapanecas el 1 de enero de 1994, bajo la dirección del subcomandante Marcos, jefe militar del Ejército Zapatista de Liberación Nacional (EZLN). Casi coincidiendo con el estallido de la revolución la sociedad civil, mexicana e internacional, de dentro y fuera del territorio mexicano, reclama el diálogo entre los contendientes y como consecuencia se celebran reuniones en la Catedral de San Cristóbal de Las Casas entre representantes del Gobierno mexicano y de las comunidades indígenas zapatistas tras el alto el fuego. Finalmente firman los representantes gubernamentales y los de las comunidades indígenas zapatistas los Acuerdos de San Andrés de 1996, en los que el Gobierno mexicano asume las propuestas indígenas. ${ }^{5}$

En efecto, el 16 de febrero de 1996 el EZLN y el Gobierno Federal firmaron los Acuerdos de San Andrés sobre "Derecho y Cultura Indígena". ${ }^{6}$ En estos acuerdos se reconoce que "los pueblos indígenas han sido objeto de formas de subordinación, desigualdad y discriminación que les han

mexicano, Barcelona, Plaza y Janés, 1999. Textos zapatistas pueden ser consultados online en Enlace Zapatista: http://enlacezapatista.ezln.org.mx/y en CEDOZ, Centro de Documentación Zapatista: http://www.cedoz.org/site/ (Consulta 02/02/19).

${ }^{3}$ Es tan abultada la bibliografía, telemática y en papel, acerca de la revolución, que la mejor vía para su conocimiento es acudir a las selecciones temáticas. Bien es verdad que se producen constantes reiteraciones en las publicaciones, muchas de las cuales por otra parte tienen un valor meramente narrativo. Una buena y actualizada selección es: BIBLIOTECA UTOPÍA, $1^{\circ}$ de enero de 2014 : a 20 años del levantamiento zapatista, Buenos Aires, Centro Cultural de la Cooperación, 2014.

${ }^{4}$ BARONNET, BRUNO, MORA, MARIANA Y STAHLER-SHOLK, RICHARD (coord.), Luchas “muy otras”. Zapatismo y autonomía en las comunidades indigenas de Chiapas, México, CIESAS/UAM/UACH, 2011. CUBELLS AGUILAR, LOLA, "Las Juntas de Buen Gobierno Zapatistas: La construcción del pluralismo a través de la lucha por la autonomía" en ORDÓÑEZ CIFUENTES JOSE E.R (coord.), Pluralismo Jurídico y pueblos indigenas. XIII Jornadas Lascasianas, México, UNAM, 2011, pp. 33-48. CORREAS, ÓSCAR, "El derecho indígena frente a la cultura jurídica dominante", en ORDÓÑEZ CIFUENTES, JOSÉ E.R., Cosmovisión y prácticas jurídicas de los pueblos indios. IV Jornadas Lascasianas, México, UNAM, 1994, pp. 95- 110. MORA, MARIANA, "La politización de la justicia zapatista frente a la guerra de baja intensidad en Chiapas" en SIERRA Ma TERESA, HERNÁNDEZ, ROSALVA A. Y SIEDER, RACHEL (eds.), Justicias Indígenas y Estado. Violencias contemporáneas. México, FLACSOCIESAS. 2013, pp. 195-227. ORDÓÑEZ CIFUENTES, JOSE E. R., Justicia y pueblos indígenas. Crítica desde la antropología jurídica, Guatemala, Instituto de Estudios Comparados en Ciencias Penales de Guatemala, 2000. ORDÓÑEZ CIFUENTES, JOSE E. R. (coord.), Pluralismo Jurídico y Pueblos Indigenas. XIII Jornadas Lascasianas Internacionales, México, UNAM, 2005. ORDÓÑEZ CIFUENTES, JOSE E. R., Derecho indígena en Mesoamérica. Caracterización epistemológica y axiológica, México, Maestría en Etnicidad, Etnodesarrollo y Derecho indígena, 2007.

\footnotetext{
${ }^{5}$ Para conocer con todo tipo de detalles el proceso negociador entre el Gobierno mexicano y los indígenas zapatistas véase BERNAL, A. y ROMERO A., Chiapas: crónica de una negociación, México, Rayuela, 1999.

6 Los Acuerdos de San Andrés constan de un Acuerdo general y tres documentos adicionales. Pueden consultarse en: http://www.cedoz.org/site/content.php?full=4 (Consulta 02/02/19).
} 
determinado una situación estructural de pobreza, explotación y exclusión política". También se afirma que "para superar esa realidad se requieren nuevas acciones profundas, sistemáticas, participativas y convergentes de parte del Gobierno y de la sociedad, incluidos, ante todo, los propios pueblos indígenas". Igualmente el Gobierno reconoció que "se requiere la participación de los pueblos indígenas, para que sean actores fundamentales de las decisiones que afectan a su vida, y reafirmen su condición de mexicanos con pleno uso de derechos", por lo tanto "esa nueva relación debe superar la tesis del integracionismo cultural para reconocer a los pueblos indígenas como nuevos sujetos de derecho, en atención a su origen histórico, a sus demandas, a la pluriculturalidad de la nación mexicana y a compromisos internacionales suscritos por el Estado mexicano, en particular el Convenio 169 de la OIT".

Estos Acuerdos también incluyen una reforma de la Constitución con los siguientes reconocimientos: la garantía del ejercicio de los derechos de los pueblos indígenas, el reconocimiento de las comunidades como entidades de Derecho público, el derecho de los municipios con mayoría indígena a asociarse libremente, la garantía de que en las legislaciones de los Estados se establezcan disposiciones para el ejercicio de la autonomía.

En síntesis, los Acuerdos tienen un profundo calado y alcance, porque no se limitan a las pretensiones de una reforma constitucional, sino que pretenden importantes cambios estructurales, institucionales y legislativas.

Comienza a continuación una política gubernamental de silencios, titubeos y engaños, que culmina en la reforma constitucional de 2001, en la que solo en pequeña parte se recogen los Acuerdos de San Andrés dejando fuera las más importantes reivindicaciones de los indígenas zapatistas. ${ }^{7}$

El 15 de marzo de 1998 se presentó definitiva e unilateralmente al Consejo de la Unión una iniciativa de reforma constitucional en materia de derechos indígenas. "La consecuencia de esto asegura López Bárcenas- fue que por varios años el debate se centró entre una propuesta legitimada

\footnotetext{
${ }^{7}$ I. ARVIDE ha publicado una relación de los errores, abstenciones, hipocresías, silencios del Gobierno mexicano en relación con las reivindicaciones de los zapatistas en La guerra de los espejos, México, Océano, 1998. El último capítulo, que es un resumen de los anteriores, se titula: "El silencio cae sobre Chiapas", pp. 207-214.
} 
socialmente, que no era iniciativa, y una iniciativa que de aprobarse amenazaba con ser una especie de aborto jurídico"8.

La reforma constitucional de 2001 no resolvió las demandas de los pueblos indígenas como expresó un comunicado del EZLN y del Congreso Nacional Indígena (CNI) el 29 de Abril de 2001. En los Acuerdos de San Andrés se planteaba la reforma de los artículos 4, 18, 26, 53, 73, 115 y 116 y por el contrario fueron finalmente reformados el 1, 2, 4, 18 y 115.

Con esta reforma se siguen imponiendo las prácticas asistencialistas, impidiendo, por tanto, que las comunidades indígenas puedan definir por ellas mismas su propio desarrollo. En cuanto a los recursos naturales no contempla el acceso, uso y disfrute colectivo, sino que está condicionado por las modalidades de propiedad y tenencia de la tierra, que ampara al latifundio en perjuicio de la propiedad comunal. En cambio se da preferencia a los intereses empresariales. No menciona cómo podrían asociarse y coordinarse los pueblos indígenas como sujetos de derecho público. Se omite la posibilidad de remunicipalización de los territorios en los cuales los pueblos indígenas se encuentran asentados. Tampoco se especifican las transferencias de competencias y funciones.

El camino a seguir por los zapatistas en su lucha por la autonomía y el reconocimiento de sus derechos no será ya de negociación o diálogo con el Gobierno mexicano, sino el de la vía de los hechos. Se centrarán en la construcción de su autonomía (que ya habían iniciado desde 1994), implantando los Acuerdos de San Andrés en su territorio.

Finalmente los zapatistas, hartos del cinismo del Gobierno mexicano, a partir de 2003 crean las Juntas de Buen Gobierno - una especie de mancomunidad de municipios- dispersas por el territorio de Chiapas, y continúan la construcción de una autonomía política de facto, que llevan a cabo a pesar de las presión y amenazas de militares y paramilitares con la doble política de atraerse a los más débiles con toda clase de ayudas y de hostigar a los más rebeldes. Hay que resaltar que el proceso de la construcción de la autonomía no arranca de las Juntas de Buen Gobierno, sino que se había iniciado antes con la creación de los Municipios Autónomos Rebeldes Zapatistas en 1994 (incluso antes).

8 LÓPEZ BÁRCENAS, F., Autonomías y derechos indígenas en México, Bilbao, Publicaciones de la Universidad de Deusto, 2006, p. 76. 
Aunque se ha destacado su importancia, las Juntas representan una etapa más de la configuración de la autonomía zapatista.

Otro hecho importante es que en la medida en que crece la autonomía de los municipios con sus cargos electos y que se crean las Juntas de Buen Gobierno, el EZLN, el brazo militar del zapatismo, declara retirarse del ámbito civil para concentrase únicamente en tareas de seguridad. Deja todo el terreno a las comunidades indígenas y a sus autoridades electas para que dirijan la marcha de la autonomía. Una promoción de la separación entre los asuntos civiles y la milicia.

En 2005 hay un importante cambio de la revolución, que se abre a la sociedad civil y a las formaciones políticas y sociales con la finalidad de construir conjuntamente un futuro para México. Es el comienzo de una nueva fase en la revolución, que abandona su aislamiento y tiende a relacionarse y luchar con colectivos afines. Es importante en este derrotero señalar la importancia de la Sexta Declaración de la Selva Lacandona, pero precisando que ya la lucha zapatista había celebrado con anterioridad reuniones nacionales e internacionales y se había abierto a la sociedad desde los comienzos de la revolución. Lo que sí marca claramente la Sexta Declaración es el distanciamiento respecto a los partidos políticos.

Como síntesis, en el proceso histórico de la revolución zapatista me atrevo a establecer las siguientes etapas significativas: a) la etapa de la guerra y la negociación con el Gobierno mexicano, b) la etapa de la ruptura con el Gobierno mexicano y el avance en la construcción de la autonomía zapatista de facto, y c) la etapa de las relaciones con los sectores progresistas de México para emprender conjuntamente una revolución compartida y deliberativa. En la primera etapa la revolución negocia con el enemigo. En la segunda, rompe con el enemigo, que le engaña, y emprende su propio proyecto político de autonomía. En la tercera, la revolución se abre y busca una revolución de todos los sectores progresistas de México y del mundo.

Diría también que la revolución va haciéndose a sí misma en el proceso. No es una revolución con objetivos claros iniciales que hay que conseguir en el proceso revolucionario. Es una revolución que constantemente se está planteando su estrategia y sus objetivos. Y ello es consecuencia de dos factores: a) la política zapatista asamblearia con sumisión del ejército a las decisiones de las asambleas; las asambleas van marcando en el proceso bélico estrategias y objetivos, y b) la conversión 
de la revolución progresivamente en revolución abierta, compartida y deliberativa con participación de colectivos sociales mexicanos.

Como colofón puede decirse que el sistema jurídico del zapatismo es autónomo no únicamente debido a las declaraciones de derechos, sino al desarrollo de la propia experiencia, ya que el sistema se va construyendo por la vía fáctica ante la falta de respuesta de las autoridades mexicanas a las exigencias de los indígenas de Chiapas.

\section{La escuela sociológica francesa. François Gény (1861-1938): la defensa de la pluralidad de fuentes del derecho frente al monopolio de la ley}

La Escuela sociológica francesa pasa por varias etapas cronológicas. Una primera inicial, en la que se va configurando la resistencia al positivismo legalista, representada por Esmein y Saleilles. Una segunda etapa de madurez dominada por la figura de François Gény. Y una última etapa, en la que las concepciones de Gény son complementadas por otros autores, como Duguit y Hauriou.

La escuela presenta ya los dos lados de las teorías sociológicas del derecho: primero, la constatación de la insuficiencia de la ley como fuente única del derecho, y segundo, la necesidad de superar esta insuficiencia reclamando la complementariedad de otras fuentes. $\mathrm{Y}$ en este cometido destaca la aportación de F. Gény, al que dedicamos una atención especial.

\subsection{F. Gény: La crítica al positivismo legalista decimonónico y al monopolio de la ley.}

La obra fundamental de Gény, Méthode d'interpretation et sources en droit privé positif (Método de interpretación y fuentes en derecho privado positivo), publicada el último año del siglo XIX, es una obra deconstructiva, que se dedica a verificar la improcedencia de la ley para resolver todos los conflictos del ordenamiento jurídico, y que necesariamente debe ser completada con otras fuentes, como la costumbre, la analogía, la equidad, la jurisprudencia y la doctrina. Se opone a elementos centrales de la Escuela de la Exégesis: la ley como fuente única del derecho, la técnica de la subsunción lógica como medio de su aplicación y la teoría de la plenitud del ordenamiento jurídico consistente en la afirmación de que los códigos del ordenamiento jurídico contienen leyes suficientes para resolver todos los casos de la realidad social. Esta labor deconstructiva le valió a Gény fuertes 
críticas, porque derribaba un edificio, que después no sustituía por otro nuevo, a las que tuvo que hacer frente con una segunda obra, a la que después me referiré.

El juez debe emprender según Gény una libre investigación científica del derecho con el objeto de completar la insuficiencia de la ley de los códigos, abarcando toda una serie de fuentes del derecho, algunas históricas y otras nuevas, producto de la racionalización del juez. Entre las primeras: la costumbre, la jurisprudencia, la doctrina, la equidad, la analogía. ${ }^{9}$ Entre las segundas: la naturaleza abstracta o principios de la justicia y la naturaleza real de las cosas; de ambas naturalezas el juez debe obtener principios y reglas para la aplicación del derecho. Tampoco hay que olvidar según Gény otras ciencias auxiliares -la sociología, la economía, la psicología-, en las que conviene que los jueces estén versados para precisar el contexto de los casos que deben resolver.

\subsection{F. Gény: La construcción de una nueva técnica jurídica: la pluralidad de fuentes formales del derecho.}

El mismo Gény reconoció las razones de las críticas a su primera obra citada y se afanó en complementarla con una segunda de carácter constructivo titulada Science et Technique en Droit Privé Positif (Ciencia y Técnica en Derecho Privado Positivo), escrita entre 1912 y 1924. Una obra, pues, de largo tiempo. Está montada sobre dos conceptos básicos: le donné et le construit, lo dado y lo construido.

No se comprende bien a Gény, si no se conoce el significado que presta a los conceptos de ciencia y técnica jurídicas. La ciencia tiene por objeto lo dado y de ahí el examen de toda clase de hechos que configuran el derecho vigente. Y la técnica tiene por objeto lo construido, tras este examen previo fáctico, es decir, la construcción de un plantel de fuentes del derecho idóneas y que permitan una real plenitud del ordenamiento jurídico imposible de alcanzar únicamente por medio de las leyes de los códigos. Lo dado y lo construido sirven así a Gény para distinguir y separar la ciencia y la técnica del derecho.

Lo dado de la ciencia jurídica se concreta en datos plurales: 1) datos naturales, tanto de carácter físico como espiritual: desde el clima a los sentimientos (en lo que Gény recuerda a

\footnotetext{
${ }^{9}$ GÉNY, F., Método de interpretación y fuentes en derecho privado positivo, Madrid, Reus, 1925, pp. 311 ss.
} 
Montesquieu cuando éste investigaba los factores que conforman las leyes de los pueblos); 2) datos históricos, que proporciona la historia del derecho y sus instituciones; 3) datos racionales, o derivados de la razón humana y 4) datos ideales, o relativos a los modelos ideales de las normas y las instituciones.

La importancia que Gény atribuye a los dos últimos tipos de datos, lejos de la realidad de los hechos y de la historia, ha justificado que algunos estudiosos le hayan catalogado dentro de la concepción iusnaturalista, ${ }^{10}$ e incluso como un restaurador del derecho natural. Esta clasificación es atrevida a mi manera de ver, y no se ajusta a la perspectiva sociológica en la que la gran mayoría de la doctrina inserta a Gény.

La técnica jurídica actúa tras las aportaciones de la ciencia jurídica con la finalidad de organizar los datos obtenidos en su investigación y sobre ellos construir unas instituciones idóneas. De la técnica jurídica forman parte las fuentes formales del derecho, denominadas por el sociólogo: las formas de exteriorización de la regulación jurídica, a las que enuncia así: la ley, la costumbre, la analogía, la equidad, la jurisprudencia, la doctrina y la tradición.

Como consecuencia la ley ya no aparece sola, como pretendían los exégetas de los códigos a todo lo largo y ancho del siglo XIX, sino que viene acompañada de otras fuentes del derecho. Pero la ley sigue siendo importante. Incluso en la lista de Gény de fuentes del derecho es citada en primer lugar. La diferencia reside en que ya no cumple la función por sí sola de completar el ordenamiento jurídico, porque éste no cabe en las leyes de los códigos, de la misma manera que tampoco la realidad social y el cambio social se pueden regular con la ley sin más. Ésta necesita de otras fuentes -las citadas por Gény- para que el ordenamiento jurídico sea pleno. En resumen, la ley es todavía la primera fuente del derecho, pero ya no es la única. Y dicho más lacónicamente: la ley no es el derecho, sino una parte del mismo.

Gény es difícil de clasificar, pues tiende un puente desde el positivismo legalista del XIX a las concepciones sociológicas del XX. Es un pionero, que aún no se ha quitado el viejo traje formalista.

\footnotetext{
${ }^{10}$ Tal es la opinión de MICHEL VILLEY en su artículo "François Gény et la renaissance du droit naturel", Archives de Philosophie du Droit, vol. VIII, 1963, pp. 197-211.
} 
Con el tiempo se ha visto que es el iniciador en Francia de una concepción sociológica del derecho, en la medida en que esta concepción era posible en su época. El destronamiento del monopolio de la ley y la defensa de una pluralidad de fuentes jurídicas catalogan a Gény como uno de los primeros sociólogos del derecho.

\section{El movimiento de derecho libre. Eugen Ehrlich (1862-1922) y Hermann Kantorowicz (1877-} 1940) la pluralidad de derechos.

Es más aceptable la denominación de movimiento que la de escuela para referirse a los juristas centroeuropeos de transición del XIX al XX y primera mitad del XX con una perspectiva sociológica del derecho, porque realmente hay tal variedad entre ellos que resulta atrevido encuadrarles en las siglas de una misma escuela. El movimiento de derecho libre también recibe el nombre de movimiento de libre investigación del derecho. Hay en el movimiento juristas pioneros y avanzados. Hay grandes diferencias entre ellos, como veremos a continuación, lo que justifica cobijarles en el paraguas de un movimiento amplio y no en la estrechura de una escuela.

\subsection{E. Ehrlich: Las etapas de su pensamiento jurídico.}

E. Ehrlich es ya un declarado sociólogo del derecho, que pone a la sociología jurídica en el peldaño más alto para comprender toda la realidad del derecho criticando al mismo tiempo el racionalismo estéril y deformador de la dogmática y el formalismo jurídico. Y muestra de ello es que su obra fundamental se titula Grundlengung der Soziologie des Rechts (Fundamentos de Sociología del Derecho), de 1913. La dogmática y el formalismo podrían servir para el estudio del derecho del Estado, pero no para captar y comprender toda la realidad del derecho, el derecho completo, que abarcaba junto al derecho estatal otros derechos. Son muchos los estudiosos que consideran a Ehrlich el fundador de la sociología del derecho y hay razones para ello, como se desprende de la explicación de su obra a continuación.

Al igual que señalábamos en Gény, también en Ehrlich podemos distinguir dos etapas: la primera crítica y la segunda constructiva. En la primera se dedica a constatar frecuentes lagunas de ley, y a ello dedica sus primeros escritos, que muestran la insuficiencia de la ley como fuente del derecho y la falsedad del principio de la plenitud del ordenamiento jurídico cifrado exclusivamente en los 
códigos. Una de estas primeras obras destructivas se titula significativamente: Über Lücken im Rechte (Sobre las lagunas en el Derecho).

La segunda etapa se inicia con la aplicación del método que denomina "libre investigación del derecho", ${ }^{11}$ que recuerda al método geniano de la investigación científica del derecho. Esta segunda etapa, de carácter constructivo, contiene ya el despliegue más extenso del pluralismo jurídico hasta entonces, rebasando ampliamente las reservas de Gény. Su obra fundamental, antes citada, Fundamentos de sociología del derecho, de 1913, es la obra más atrevida de defensa del pluralismo de fuentes del derecho y también la más fundada hasta su fecha.

\subsection{E. Ehrlich: La pluralidad de derechos.}

Distingue Ehrlich hechos normativos y derechos. ${ }^{12}$ Los primeros producen a los segundos. Hechos normativos son los factores que originan el derecho en sus múltiples manifestaciones. Cita entre estos hechos: el uso, el dominio, la posesión y la declaración de voluntad. ${ }^{13}$ Estos hechos normativos dan lugar a una serie de derechos. El derecho inicial y primario es el derecho social creado por la sociedad, que ya contiene una serie de instituciones básicas de origen social: el matrimonio, la familia, las corporaciones, la posesión, el contrato y la sucesión. Estas instituciones no necesitan para existir la ley del Estado. Posteriormente se van formando los otros derechos: el derecho del Estado, el derecho de los jueces, el derecho de la doctrina. Todos ellos constituyen el derecho u ordenamiento jurídico completo.

Viene a continuación del derecho social el derecho de los jueces y de los juristas, que se basan en decisiones, e intentan resolver los conflictos que se generan en el intercambio social. En último lugar, el derecho del Estado, basado en normas que se imponen coactivamente, y que aparece cuando el relieve de los conflictos en la sociedad es tal que es necesaria la norma coactiva del Estado.

\footnotetext{
11 A principios del siglo XX, en 1903, escribió Ehrlich un escrito-manifiesto en defensa del pluralismo de fuentes del derecho, Freie Rechtsfindung und Freie Rechtswissenschaft (Libre indagación y libre ciencia del derecho) Tuvo una extraordinaria resonancia en los medios intelectuales alemanes.

12 EHRLICH habla de derechos y no de fuentes de derecho, pero ambas acepciones se identifican, puesto que los derechos -derecho social, derecho judicial, derecho doctrinal, derecho estatal- pueden ser calificados como fuentes jurídicas.

${ }^{13}$ EHRLICH, E., Grundlegung der Soziologie des Rechts (Fundamentos de Sociología del Derecho), Berlin, Duncker und Humblot, pp. 67 ss. Ehrlich nos dejó en el mismo año de su muerte, en 1922, un compendio de su visión del pluralismo jurídico en un breve artículo, "Sociologia del Diritto", publicado en la Rivista Internazionale di Filosofia del Diritto, 1922, pp. 96-110.
} 
Hay así una genética de factores productores de derecho y de derechos producidos. Los derechos se ordenan cronológicamente y jerárquicamente según Ehrlich y aquí es donde reside su impostura respecto a la oficialidad de su época, porque pone en primer lugar al derecho de la sociedad. Este derecho no sólo es el primero que se genera sino el primero en la jerarquía de los derechos. Primero surgió el derecho social, a continuación el derecho de los jueces y juristas y finalmente el derecho estatal.

En la captación de la evolución del derecho y de la formación de los derechos hay que tener en cuenta la influencia en el autor de su formación romanista. Una buena instrucción en el derecho romano era por lo demás una formación exigida a los preclaros juristas de la época del jurista alemán. La conformación y la evolución del ius privatum y del ius publicum, procedentes de diferentes fuentes jurídicas, a la que él alude en sus escritos, fue abriéndole el camino hacia el pluralismo de derechos.

\subsection{H. Kantorowicz: la prioridad de la jurisprudencia como fuente del derecho.}

H. Kantorowicz es la "oveja negra" de su época y el grupo de juristas abiertos a la sociología del derecho y el pluralismo jurídico, porque se va al polo opuesto de la ideología del positivismo legalista y la Escuela de la Exégesis. Si éstos no concebían otra fuente del derecho que no fuera la ley, Kantorowicz considera que la fuente prioritaria del derecho es la decisión de los jueces, respecto a la cual la ley es una orientación. ${ }^{14}$ Una coincidencia con el realismo jurídico posterior, que definirá a la ley como una predicción de la verdadera norma, la sentencia de los jueces. Pero las posiciones del realismo jurídico son posteriores en el tiempo y contaban ya con el camino desbrozado por Kantorowicz, quien golpeado por una fuerte crítica llegó a retractarse de sus ideas.

En efecto, hasta los escritos de Kantorowicz la ley había sido combatida, pero no a tal punto de sustituirla por las decisiones de los jueces en la pirámide de las normas. Decir, como él argumentaba, que la principal fuente del derecho era la sentencia judicial, suponía un plato muy fuerte para la época.

En su obra fundamental Der Kampf um die Rechtswissenchaft (La lucha por la ciencia del derecho), de 1906, escrita con el seudónimo Gnaeus Flavius para evitar la animosidad de sus colegas, traza un nuevo y revolucionario programa con los siguientes puntos:

${ }^{14}$ KANTOROWICZ, H., Der Kampf um die Rechtswissenschaft, Heildeberg, Winter, 1906, pp. 15ss. 
a) un sistema de fuentes, en el que la fuente prioritaria es la sentencia judicial, siendo las demás fuentes, inclusive la ley, fuentes de apoyo y orientación de esta fuente prioritaria.

b) como consecuencia los jueces adquieren un primer plano, y por ello su formación debe ser mayor para no equivocarse en la declaración de la solución de los casos, que se someten a su juicio. No basta la formación estrictamente jurídica, pues ya no son meros aplicadores de normas, sino casi legisladores. Y en esta formación no podía faltar el conocimiento de la sociología y la psicología. Tanta importancia tenía para Kantorowicz la formación de los jueces que consideraba que en sus manos estaba la posibilidad de la mejora del derecho y no en los legisladores. Hay una frase paradigmática del autor alemán: “de la cultura de los jueces pende en último término el progreso del derecho". ${ }^{15}$

c) la sustitución de la dogmática escolástica por una nueva metodología: la libre creación del derecho. Ahora se trata de promover la discrecionalidad judicial en la formulación del derecho. La libre creación del derecho en manos de los jueces vulneraba principios jurídicos tradicionales conquistados en la lucha por el Estado de Derecho: la generalidad de las normas, la certeza jurídica, la seguridad jurídica. Es fácil comprender que Kantorowicz se viera obligado a retractarse.

\section{La teoria sociológica del derecho europea y las concepciones jurídicas zapatistas en México}

No parece haya una gran distancia entre los primeros sociólogos de derecho europeos y los defensores del derecho zapatista de Chiapas. Aquéllos proclaman una pluralidad de fuentes del derecho contra la única ley del Estado. Los indígenas zapatistas y sus partidarios también proclaman una pluralidad de fuentes frente a la ley del Estado mexicano. Pluralismo jurídico en unos y otros.

Los zapatistas se encuentran en cierta medida próximos a Gény en el tema de la pluralidad de fuentes del derecho, aunque ponen al revés la pirámide normativa del sociólogo jurídico francés. La ley, que en Gény es la primera fuente del derecho, si bien no es la única, en los zapatistas es una fuente dependiente del derecho consuetudinario. Entendiendo por ley indígena la emanada de las asambleas de las comunidades, donde se practica una democracia directa. No la ley del Estado mexicano, a la que

${ }^{15}$ KANTOROWICZ, H., ob. cit., p. 48 
rehúyen los indígenas, porque una de sus grandes reivindicaciones es la del reconocimiento de un sistema jurídico propio y autónomo, que abarque a las normas indígenas y a los órganos que las elaboran y aplican. En estas comunidades actualmente la ley indígena es la ley de las asambleas de las comunidades en la medida que el Estado mexicano, vigilante y hostigante, no obstante deja en cierta medida que los indígenas zapatistas construyan su propia autonomía política y apliquen su propio derecho.

En relación con Kantorowicz el paralelismo del derecho indígena zapatista se sitúa en el hecho de prestar atención y acudir a la asamblea de las comunidades para la resolución de los casos difíciles e innovadores. Lo que quiero decir es que los indígenas zapatistas valoran mucho las competencias de sus jueces al igual que hace el jurista alemán otorgando a los jueces y sus sentencias un valor especial. Pero hay otra semejanza más interesante. Kantorowicz señala que los jueces deben ser expertos sociólogos formados en las ciencias sociales y en la práctica social para acertar con la siempre difícil tarea de encontrar la solución más justa para los conflictos. Y precisamente uno de los principios del zapatismo es el aprendizaje social de los indígenas desempeñando temporal y rotativamente todos los cargos públicos ${ }^{16}$.

El parangón con Ehrlich es extraordinario, no solo en la presentación de una pluralidad de derechos, sino en la forma de entrelazarse estos derechos. De la misma manera que el jurista alemán sostiene la prioridad del derecho social, generado por la sociedad y concretado en instituciones sociales antes de su reconocimiento por la ley del Estado, así también los indígenas zapatistas refieren la prioridad de su derecho consuetudinario ${ }^{17}$, el derecho emanado de sucesivas generaciones durante siglos, trasmitido oralmente, que los indígenas asumen con un vínculo obligatorio. Cuando los

\footnotetext{
16 "Ahora estamos pasando el trabajo de vigilancia del buen gobierno a las bases de apoyo zapatistas, con cargos temporales que se rotan, de modo que todos y todas aprendan y realicen esa labor". Texto completo de la Sexta Declaración de la Selva Lacandona en: http://enlacezapatista.ezln.org.mx/sdsl-es/ (Consulta: 04/02/2019).
}

\footnotetext{
${ }^{17}$ Los indígenas zapatistas se refieren a su propio derecho con varias denominaciones: derecho ancestral, derecho consuetudinario, usos y costumbres. Derecho ancestral es el conjunto de normas transmitidas de generación en generación en el seno de las comunidades indígenas, cuyos orígenes se sitúan en tiempos muy remotos; de ahí que se le dé el nombre de derecho ancestral. También es denominado este derecho como derecho consuetudinario. Es equivalente a lo que entendemos como derecho consuetudinario en la cultura occidental con la salvedad de que es una fuente primaria del derecho para los indígenas y no supeditada a otra norma superior. También es equivalente a la denominación "usos y costumbres", que fue establecida por el conquistador hispano. Con esta denominación se le quería quitar relevancia y desconocer su valor como derecho propiamente. Eran simples prácticas de los nativos, faltas de lógica y coherencia, meramente repetitivas, pues generaciones pasadas, presentes y futuras reiteran el mismo comportamiento de una manera irreflexiva. Es una terminología creada por el colonizador con un desconocimiento de los valores del derecho indígena.
} 
zapatistas se refieren a su derecho normalmente utilizan la denominación "ancestral” o "consuetudinario". Es muy frecuente en los textos zapatistas la denominación "derecho consuetudinario" con el alcance de derecho propio de los indígenas ${ }^{18}$. Cuando emplean el término "usos y costumbres" es por concesión a la manera como los otros llaman al derecho indígena.

El que este derecho sea un derecho construido generacionalmente no significa que sea un derecho cosificado e inamovible. Es una visión de este derecho muy extendida que no responde a la realidad. Es un alegato producto de la ignorancia de los críticos del derecho indígena, al que denuncian por su arcaísmo contrario a las necesidades de los nuevos tiempos. Por el contrario, el derecho indígena evoluciona en un doble sentido. Primero, porque nuevas normas sociales vienen a incorporarse a él con el discurrir de los tiempos y las necesidades. Segundo, porque las mismas normas cambian con el tiempo. El derecho indígena está formado por normas e instituciones, que evolucionan, nacen, cambian y desaparecen. La diferencia con el derecho estatal reside en que carece de un acto de promulgación y un acto de derogación, que indiquen expresamente cuándo las normas del derecho indígena comienzan a estar vigentes y cuándo pierden su eficacia al ser derogadas. Pero incluso el derecho del Estado contiene normas que se parecen a las normas del derecho indígena: las costumbres jurídicas que aparecen y desaparecen sin la concurrencia de un acto concreto de promulgación o derogación, sino por la práctica de las mismas por la sociedad o el abandono y desuso.

E igualmente el que este derecho consuetudinario se transmita oralmente no quita que en algunos lugares se proceda a su escrituración, que está suscitando graves críticas ${ }^{19}$.

Este derecho de la sociedad es en Ehrlich prioritario en su valor y en el tiempo. Es el primero que se crea y es además el más valioso, como hemos visto. Igual opinión tienen los indígenas zapatistas

\footnotetext{
${ }^{18}$ Como muestra un texto zapatista de la explicación de los municipios autónomos en el comienzo de la instauración de la autonomía política de facto: "Dejados en abandono total por las instituciones del estado, sin servicios básicos, los indígenas intentaron con el municipio autónomo resolver problemas locales de convivencia, relación e intercambio entre comunidades y atender a delitos menores. En la aplicación de justicia se basaban en el derecho consuetudinario" (EZLN, Documentos y comunicados, Vol. 4, México, Era, 2003).

${ }^{19}$ Este proceso de codificación, no obstante su alcance muy limitado, está provocando opiniones variadas en la doctrina: unas a favor y otras en contra. Las críticas más extendidas alegan que la codificación cosifica un derecho evolutivo como el indígena, y que este derecho es tan diverso que sería inalcanzable la codificación. La virtud de la codificación más señalada es que aumentaría el conocimiento del derecho indígena, siendo además un acicate para su propagación, con lo que se convierte en un seguro contra su desaparición debido a la insuficiencia de la transmisión oral y a la deformación, que produce en las señas propias del derecho.
} 
de su derecho consuetudinario, el derecho social en términos ehrlichianos: el primero en el tiempo y el primero en valor en comparación con otros derechos.

En efecto, el derecho consuetudinario indígena es anterior en el tiempo y el más relevante. Es anterior porque es el derecho creado espontáneamente, de generación en generación, desde el principio de los tiempos. Y es el más relevante porque es el derecho vinculado a la conciencia de los indígenas, que consideran a la tradición dotada de un valor esencial.

La relevancia que los indígenas zapatistas conceden a su derecho no se corresponde con la opinión que de él suelen tener los representantes y autoridades del Estado mexicano y un sector doctrinal. Cuando se habla de "armonizar" el derecho indígena con las constituciones estatales, los Gobiernos se refieren a la jurisdicción indígena de delitos menores. No se atreven a emplear una terminología jurídica de mayor entidad. Mucho menos referirse al derecho indígena como "sistema de derecho" o "sistema normativo". El derecho indígena es como "un derecho para andar por casa" y siempre en la casa de los indígenas. Un derecho para conflictos internos de escasa monta. Para los grandes conflictos está el superior derecho del Estado. Pero cada vez es mayor el número de opiniones en los estudiosos de la cultura occidental, que destacan los valores de la cultura indígena ${ }^{20}$.

La relevancia de este derecho consuetudinario indígena se basa en varios argumentos. El primero es el sentido comunitario que los indígenas tienen de su derecho y en general de las reglas de comportamiento. El segundo es el carácter de derecho nativo destruido por los colonizadores con el que mantienen un vínculo esencial desde los orígenes de los tiempos.

Veamos ambos argumentos:

\footnotetext{
${ }^{20}$ Valores de la cultura indígena presentados muchas veces en contraste con la cultura occidental u otras culturas. Daniel Oliva y Diego Blázquez opinan que los derechos de los pueblos indígenas están basados en el valor de la libertad, la igualdad y la diversidad, y se conforman como "normas protectoras de la identidad cultural diferenciada que asegura la autonomía y dignidad cultural de las personas indígenas y que pueden así realizar aportaciones significativas al desarrollo compartido y la ética global [...] deben ser contemplados como instrumentos favorecedores del diálogo intercultural, la paz, la convivencia y la solidaridad internacional" (OLIVA MARTÍNEZ, D., y BLÁZQUEZ MARTÍN, D., Los derechos humanos ante los desafios internacionales de la diversidad cultura, Valencia, Tirant Lo Blanch, 2007, p. 220) José Luis López Fuentes, después de hacer un estudio de casos jurídicos indígenas, llega a compendiar las notas de derecho indígena de esta manera: integral porque engloba a toda la comunidad, basado en la tradición cultural de la comunidad, dinámico y versátil, adaptándose a la situación del momento, a la propia dinamicidad natural de la práctica comunitaria, promotor de la reinserción del individuo antes que el rechazo o castigo, promotor de la armonía comunitaria, ya que la autoridad debe obedecer a lo que la comunidad establezca en la asamblea (LÓPEZ FUENTES, J. L., Los derechos de los pueblos indígenas, Málaga, Centro de Ediciones de la Diputación de Málaga, 2006, p. 82)
} 
A) En las comunidades indígenas zapatistas destaca sobremanera el sentido colectivo y comunitario del derecho y de sus manifestaciones. La propiedad, la tierra, la cultura... todo es colectivo siendo el referente la comunidad y no los individuos que la componen.

Los derechos indígenas son normas de la comunidad y no del individuo como tal. Los derechos liberales occidentales son normas derivadas de la propia naturaleza de la persona y preexistentes a la creación de la comunidad. Aquí, la comunidad, ya sea social o estatal, es posterior a la existencia de estas normas cuyo entramado principal son los derechos de la persona. Los indígenas, en cambio, no tienen este sentido individualista y previo a la comunidad de las normas reguladoras de su convivencia, pues estas normas lo son de la comunidad y del individuo en cuanto forma parte de la comunidad.

No entra en la lógica del derecho indígena zapatista -y en general de los derechos indígenas- la lógica individualista liberal. Pongamos algunos ejemplos. El trabajo familiar para la comunidad no responde al trabajo individual y su individual retribución. La concepción indígena de la tierra y sus productos (persona y tierra en un todo) no responde al derecho individual de la propiedad y su derivado derecho de enajenación; un indígena no puede vender la tierra, porque ésta forma parte de sí mismo. La expoliación del entorno natural tan frecuente en Occidente no responde al sagrado respeto de los indígenas hacia el medio natural donde viven y que los mantienen. Hasta el proceso y el derecho penal tienen este sentido colectivo, pues la mediación ${ }^{21}$ es una práctica habitual en el desarrollo del proceso y en la aplicación de las sanciones ${ }^{22}$.

Junto a los textos zapatistas transcritos en las notas anteriores, oigamos el informe de $P A Z C O N$ $D E M O C R A C I A$, asociación surgida del conflicto de Chiapas, que envió una misión de observación, formada por personas de gran prestigio social y talante independiente, a las comunidades indígenas zapatistas para elaborar un informe de la situación y un plantel de propuestas. El informe, tras numerosas entrevistas en las comunidades, concluía en el apartado "Impartición de justicia" de esta manera: "Se prefiere casi siempre la reparación del daño, el trabajo comunal, el convencimiento y la reflexión sobre quienes mantienen conductas o realizan acciones no aprobadas por la comunidad...En

\footnotetext{
${ }^{21}$ Un párrafo de "La Treceava Estela", texto de la revolución zapatista, dice así: "En el caso de las denuncias que recibe la Comandancia se turnan al Comité de Zona para investigar su veracidad y, en caso positivo, solucionar el problema juntando a las partes para hacer acuerdo".

${ }^{22}$ Hay una frase corta de la Treceava Estela de la revolución zapatista que expresa este sentido comunitario del derecho penal indígena: "El responsable es castigado obligándolo a hacer colectivo y a reponerle a la comunidad lo que tomó indebidamente".
} 
los conflictos entre particulares operan la conciliación, la negociación entre las partes hasta llegar a un acuerdo satisfactorio para ellas",23.

El sentido colectivo y comunitario del derecho indígena, que sale de la comunidad y la comunidad lo aplica, nos indica claramente que el derecho consuetudinario, transmitido de generación en generación por las comunidades, reviste un especial valor para los indígenas.

B) El valor de este derecho consuetudinario indígena resplandece cuando entra en colisión con el derecho del Estado, porque en estos casos de conflicto los indígenas se refieren a su derecho como el derecho nativo, una especie de derecho natural, anterior al derecho estatal y que éste debe asumir y respetar. Un derecho injustamente destruido por el conquistador hispano y sustituido por un derecho imperial que en nada se ajustaba a la cosmovisión y patrimonio de creencias y comportamientos de los indígenas. En la colonización de las Indias la Corona española creó un derecho especial para controlar las poblaciones originarias del "nuevo mundo". A este orden jurídico especial lo llamó "derecho indiano". Este derecho está formado por dos elementos básicos: el derecho creado expresamente para las colonias y el derecho castellano que se usaba en caso de no disponer de normas especiales para las colonias. También formaba parte de este derecho en una dimensión muy menor cualitativa y cuantitativamente las normas del derecho indígena aceptado y reconocido por la Corona y sus autoridades ${ }^{24}$.

\footnotetext{
${ }^{23}$ Informe completo del organismo civil PAZ CON DEMOCRACIA titulado "México: Balance de las Juntas de Buen Gobierno. Chiapas y la Alternativa zapatista" en: https://docplayer.es/40222003-Las-alternativas-zapatistas.html (Consulta: 02/02/2019).

${ }^{24}$ Hay que distinguir entre el derecho indígena practicado por los indígenas y el derecho indígena que el Estado acepta. Una distinción tanto más relevante cuanto más se separa uno de otro derecho: el derecho real de los indígenas y el mínimo derecho indígena aceptado por el Estado, que especialmente acontece en fases históricas primarias de relación antagónica del Estado y los pueblos indígenas. Es cuando el mínimo derecho indígena estatal contrasta con el extenso derecho indígena real. La separación es aún mayor cuando el Estado legisla un derecho para los indígenas contradictorio con el derecho que éstos practican. Es ésta una distinción no frecuente en los tratadistas. Creo que en ella entra López Fuentes cuando habla de "derecho indígena" y "derechos indígenas". El derecho indígena es para él "el derecho propio que se produce desde los mismos pueblos indígenas", mientras que los derechos indígenas son "todos los derechos de los pueblos indígenas reconocidos por el Estado y materializados en la Constitución, las leyes, los reglamentos u otros instrumentos jurídicos" (LÓPEZ FUENTES, J. L., Los derechos de los pueblos indígenas, Málaga, Centro de Ediciones de la Diputación de Málaga, 2006, p. 43).
} 
También fue postergado el derecho indígena en México en el periodo republicano posterior a los reinos hispanos. Con las revoluciones americana y francesa llegaron los aires de la ideología liberal de la época y sobre ella se fundaron los nuevos Estados latinoamericanos, la conversión de los reinos de la Corona de España en nuevas repúblicas. Los nuevos Estados centralizaron el poder que ejercían sobre el territorio y sus habitantes. Crearon un sentimiento de pertenencia a la nación, de conciencia nacional, establecieron una lengua oficial, fomentaron valores comunes y crearon un sistema jurídico propio, un Derecho único en el territorio del Estado.

En las Indias del Imperio hispano y en las Repúblicas de los Estados independientes latinoamericanos siempre se vivió una tensión jurídica entre el derecho oficial del Estado y los derechos de las culturas indígenas y una tensión sociológica entre la realidad social del derecho practicado y la imposición del derecho oficial por las autoridades del Estado.

Después - continuamos con Ehrlich- viene el derecho de los jueces y el derecho de la doctrina. Y también el derecho indígena se surte de las decisiones de los jueces y de la doctrina. Los jueces indígenas aplican y adaptan el derecho consuetudinario a los nuevos tiempos y sus necesidades. Y los consejos de jueces son, al mismo tiempo, guardianes del derecho y órganos que deliberan y resuelven los casos difíciles. Como los altos tribunales de justicia de las democracias parlamentarias, también los consejos de jueces de las comunidades indígenas zapatistas "sientan jurisprudencia".

\section{Conclusiones.}

La conclusión de este artículo es la respuesta afirmativa a la hipótesis formulada en la introducción. Efectivamente podemos establecer un claro parangón entre los sociólogos del derecho europeos, cuyas concepciones jurídicas hemos examinado en la primera parte de este trabajo, y las concepciones acerca del derecho de los zapatistas chiapanecos.

Hemos visto que en Gény hay una ciencia jurídica basada en el examen de los datos físicos y espirituales y una técnica jurídica, que es la formulación de las fuentes del derecho socavando la primacía de la ley. Gény presenta a la ley como la principal fuente del derecho, pero no es la única, porque a la ley acompañan otras fuentes: la costumbre, la analogía, la equidad, la jurisprudencia, la doctrina y la tradición. La coincidencia con los zapatistas es clara, porque también éstos se oponen al 
monopolio de la ley (en su caso la ley del Estado) y defienden una pluralidad de fuentes jurídicas, y entre ellas las costumbres de la tradición y los acuerdos tomados en las asambleas. Y hay otra curiosa coincidencia con Gény: la valoración de la experiencia como marco en la conformación del derecho, de la misma manera que Gény valoraba los datos (les donnés) para la conformación de la técnica jurídica, cuyo objetivo era la formulación de un abanico de plurales fuentes del derecho.

En Ehrlich, avanzando sobre las posiciones tímidas de Gény, ya encontramos una pluralidad de derechos: a) el derecho social, el derecho primario y más importante, creado por la sociedad, que ya contiene una serie de instituciones básicas de origen social: el matrimonio, la familia, las corporaciones, la posesión, el contrato y la sucesión, b) el derecho de los jueces, c) el derecho de la doctrina, y d) el derecho del Estado Todos ellos constituyen el ordenamiento jurídico completo. Es curioso constatar la prelación que hace de estos derechos, al contrario del positivismo dominante en Europa en su época, porque en la sucesión de derechos indicados coincide la cronología o sucesión en el tiempo y la relevancia. El más relevante es el derecho de la sociedad; el menos relevante es el derecho del Estado, porque este derecho confluye con su norma coactiva cuando los conflictos no han podido ser solucionados por los otros derechos. La oposición del autor alemán a la teoría jurídica formalista de su época no puede ser más radical, porque el derecho de la sociedad es el primero en la cronología y en el valor: el primero en la producción jurídica y también el primero en la escala de valores.

La coincidencia de Ehrlich con las apreciaciones de los zapatistas sobre el derecho es doble y muy significativa. La coincidencia de produce en dos puntos: la diversidad de fuentes del derecho en primer término y el carácter prioritario en el tiempo y en el valor del derecho consuetudinario indígena, equivalente al derecho social ehrlichiano,

Kantorowicz es menos aprovechable que los anteriores sociólogos-juristas en el análisis comparativo, porque se sitúa en el lugar opuesto a la ley, destacando como principal fuente del derecho a las decisiones judiciales, respecto a las que la ley es una orientación o programa. Hasta cierto punto puede decirse que es un cambio de un monismo jurídico por otro; ahora se pone la sentencia del juez en el lugar de la ley. Un ataque a la línea de flotación de la escuela de la exégesis y el formalismo jurídico predominante en Europa a lo largo del siglo XIX. Aunque la posición del jurista alemán -bien 
radical para su tiempo- sería posteriormente rebasada por las concepciones del realismo jurídico, tanto en Europa como en los Estados Unidos de América.

Como ahora las decisiones de los jueces son tan relevantes, el autor predica la necesidad de la formación de los jueces, ya que la virtualidad del derecho está colocada en sus manos y no tanto en las del legislador.

Hay que destacar un punto de conexión fuerte entre Kantorowicz y el movimiento zapatista: la exigencia de la formación de los jueces, ya que según él cumplen un papel de cuasi-legisladores, y deben adquirir experiencia y conocimiento de la realidad para ejercer bien sus funciones. Precisamente los zapatistas ponen mucho empeño en que todos los miembros de la comunidad roten en el desempeño de los cargos públicos, entre ellos los de la administración de justicia, para conseguir la formación que da la experiencia. El sistema político zapatista, basado en la rotación de los cargos públicos, es un instrumento adecuado para la formación en la experiencia y el ejercicio de responsabilidades. 


\section{Bibliografía}

ACUERDOS DE SAN ANDRÉS: http://www.nodo50.org/pchiapas/chiapas/documentos/sandres1.htm

ARVIDE, I., La guerra de los espejos, México, Océano, 1998.

EDICIONES DEL SERBAL, Chiapas: la palabra de los armados de verdad y fuego, 2 vols., Barcelona, Ediciones del Serbal, 1994. EZLN, Documentos y comunicados I-IV, México, Era, 1994-2003.

EZLN, Libertad, democracia y justicia, delirio del EZLN, México, s/e, 1996.

EZLN, Declaraciones de la Selva Lacandona, I-VI, México, s/e, 1993. http://www.nodo50.org/pchiapas/chiapas/documentos/selva.htm.

EZLN, Documentos y comunicados, Vol. 4, México, Era, 2003.

BERNAL, A. y ROMERO A., Chiapas: crónica de una negociación, México, Rayuela, 1999.

BIBLIOTECA UTOPÍA, $1^{\circ}$ de enero de 2014: a 20 años del levantamiento zapatista, Buenos Aires, Centro Cultural de la Cooperación, 2014.

EHRLICH, E., Grundlegung der Soziologie des Rechts, Berlin, Duncker und Humblot, 1967.

EHRLICH, E., “Sociologia del Diritto", Rivista Internazionale di Filosofia del Diritto, 1922, pp. 96-110.

GÉNY, F., Método de interpretación y fuentes en derecho privado positivo, Madrid, Reus, 1995

KANTOROWICZ, H., Der Kampf um die Rechtswissenschaft, Heildeberg, Winter, 1906.

LÓPEZ BÁRCENAS, F., Autonomías y derechos indígenas en México, Bilbao, Publicaciones de la Universidad de Deusto, 2006.

LÓPEZ FUENTES, J. L., Los derechos de los pueblos indígenas, Málaga, Centro de Ediciones de la Diputación de Málaga, 2006.

OLIVA MARTÍNEZ, D., y BLÁZQUEZ MARTÍN, D., Los derechos humanos ante los desafios internacionales de la diversidad cultura, Valencia, Tirant Lo Blanch, 2007.

SUBCOMANDANTE MARCOS y LE BOT, YVON, El sueño zapatista, Barcelona, Anagrama, 1997.

SUBCOMANDANTE MARCOS, La Treceava Estela, Julio de 2003. http://www.nodo50.org(pchiapas/chiapas/documentos/calendas/chiapas2.htm.

SUBCOMANDANTE MARCOS. Desde las montañas del sureste mexicano, Barcelona, Plaza y Janés, 1999.

VILLEY, M., "François Gény et la renaissance du droit naturel", Archives de Philosophie du Droit, vol. VIII, 1963, pp. 197-211. 